\title{
INFLUÊNCIA DO TEOR DE FIBRAS NA RESISTÊNCIA AO IMPACTO DE COMPÓSITOS HIPS/FIBRAS DE COCO VERDE APLICADOS PARA POSSÍVEL APLICAÇÃO NA INDÚSTRIA AUTOMOBILÍSTICA
}

\author{
Gilmara Brandão Pereira ${ }^{1}$ \\ Glayce Cassaro Pereira² \\ Márcio Alves de Lima ${ }^{3}$ \\ Sérgio Roberto Montoro 4
}

\begin{abstract}
Resumo: Existe uma tendência mundial em buscar recursos naturais alternativos em substituição às fibras sintéticas. Diante deste cenário, as fibras naturais vegetais, como por exemplo, a fibra da casca do coco verde, é uma excelente alternativa por possuírem boas propriedades mecânicas e térmicas. Essas fibras, além de seu baixo custo, são biodegradáveis e de fonte renovável. No presente trabalho foram caracterizados compósitos poliméricos de HIPS reforçados com fibras naturais provenientes da casca do coco verde. Foram caracterizadas três famílias de compósitos, nas proporções de 10, 20 e $30 \%$ ( $\mathrm{m} / \mathrm{m})$. Foi possível constatar que a adição da fibra de coco ao HIPS acarretou uma diminuição na resistência ao impacto, quando comparados ao HIPS puro. Dessa forma, com a adição de fibras de coco verde no HIPS obteve-se um material com até 30\% menos polímero e com propriedades mecânicas viáveis para determinadas aplicações do HIPS.

Palavras-chave: Compósitos; HIPS; Fibras de coco verde; Resistência ao impacto.
\end{abstract}

\footnotetext{
1 Mestrado Profissional em Materiais/UniFOA, Brasil. E-mail: brandaoconsultoria.treinamento@gmail.com,

2 Mestrado Profissional em Materiais/UniFOA, Brasil. E-mail: glaycecp@yahoo.com.br,

${ }^{3}$ Mestrado Profissional em Materiais/UniFOA, Brasil. E-mail: marcioalvestna@hotmail.com,

${ }^{4}$ Mestrado Profissional em Materiais/UniFOA, Brasil. E-mail: sergio.montoro@foa.org.br.
} 